\title{
PERFIL DOS DISCENTES DO PROGRAMA DE PÓS-GRADUAÇÃO EM ENGENHARIA TÊXTIL DA UFRN
}

DOI: 10.37702/2175-957X.COBENGE.2021.3676

Macielly Silva Borges - maciellyborges@gmail.com

SEDUC Maranhão

Avenida Moema Tinoco da Cunha Lima 2311

59136-245 - Natal - RN

Andreza Bernardes da Silva - andrezabernardes@outlook.com

Universidade Federal do Rio Grande do Norte

Rua Franklin Magalhães 720

04374-000 - São Paulo - SP

lêda Letícia de Souza Ferreira - iedaleticiasf@gmail.com

Universidade Federal do Rio Grande do Norte

Rua Monsenhor Augusto Franklin 31

59060-560 - Natal - RN

Lucas Gomes Miranda Bispo - lucasgmb17@gmail.com

Universidade Federal do Rio Grande do Sul

RUA AMÂNIO PEREIRA 12

48605-610 - PAULO AFONSO - BA

Resumo: Este trabalho teve como objetivo avaliar o perfil dos discentes do programa de pós-graduação em Engenharia Têxtil na Universidade Federal do Rio Grande do Norte (UFRN). Para tal, foram coletados dados por meio de um questionário disponibilizado aos alunos das turmas 2019.1, 2020.1 e 2021.1. O método para interpretar os dados foi qualitativo com base na amostra populacional. Como resultado, foi possível observar que a maior parte dos alunos são do gênero feminino, com predominância etária abaixo dos 30 anos e provenientes, principalmente, do Rio Grande do Norte. Acerca da formação superior, em geral, são engenheiros têxteis, como também de outras engenharias e cursos. quanto ao vínculo empregatício, Alguns nunca trabalharam na área, outros estão trabalhando enquanto realizam o curso e uma pequena parcela é bolsista. Com relação ao conhecimento do curso, muitos souberam por meio de professores da graduação ou por mídias eletrônicas. A escolha está relacionada 
principalmente pelo aprofundamento dos conhecimentos e ter uma melhor qualificação e interesse pela área. Grande parte pretende seguir a carreira acadêmica e creem que o curso é fundamental para sua profissão. Os dados obtidos são de relevância para avaliar o perfil dos alunos e o curso para a área têxtil, como também um estudo para que a universidade possa entender as expectativas dos alunos e realizar ações para atendê-las, e assim abastecer o mercado com profissionais especializados na área têxtil.

Palavras-chave: Perfil do aluno. Pós-graduação. Engenharia Têxtil. Escolha do curso. Motivação. 


\section{PERFIL DOS DISCENTES DO PROGRAMA DE PÓS-GRADUAÇÃO EM ENGENHARIA TÊXTIL DA UFRN}

\section{INTRODUÇÃO}

Um dos objetivos da educação é formar cidadãos críticos, autores do seu próprio conhecimento; capazes de analisar, refletir e se posicionar para tomadas de decisão, no que se refere a si mesmo e na sociedade na qual estejam inseridos. Segundo a Lei de Diretrizes e Bases (LDB), a educação abrange os processos formativos que se desenvolvem na vida familiar, na convivência humana, no trabalho, nas instituições de ensino e pesquisa, nos movimentos sociais e organizações da sociedade civil e nas manifestações culturais. Na qual, possui finalidade o pleno desenvolvimento do sujeito, sua construção para o exercício da cidadania e sua qualificação para o mercado de trabalho (BRASIL, 1996).

Os cursos de pós-graduação se enquadram no quesito de preparo do indivíduo para uma excelente qualificação no âmbito profissional e acadêmico. Visando preparar educadores, pesquisadores e profissionais que atuem nas mais diversas áreas do conhecimento. Atualmente no Brasil, há apenas dois cursos de pós-graduação em Engenharia Têxtil, a nível de mestrado, nas instituições de ensino: Universidade Federal do Rio Grande do Norte (UFRN) e Universidade Federal de Santa Catarina (UFSC). (2020).

O primeiro curso de mestrado em Engenharia Têxtil no Brasil foi implementado na UFRN no ano de 2017, para suprir a demanda crescente no mercado na região, por possuir diversas indústrias do ramo têxtil. A área de concentração do curso é Têxteis avançados e o programa tem 2 linhas de pesquisa, que são: Têxteis técnicos e Química têxtil (UFRN, 2016). Devido a carência de cursos de pós-graduação nessa área no Brasil, a UFSCcampus Blumenau, criou o segundo mestrado em Engenharia Têxtil, no qual se busca aperfeiçoar os assuntos estudados pelos alunos na graduação e qualificar profissionais desse mercado. A área de concentração do programa é Desenvolvimento de processos e produtos têxteis, com as seguintes linhas de pesquisa: Engenharia de processos e produtos têxteis; Sustentabilidade no setor têxtil; e têxteis técnicos, inteligentes e funcionais (UFSC, 2018).

Com base no Projeto Político Pedagógico do curso de Engenharia Têxtil da UFSC Blumenau (UFSC, 2013), a área têxtil representa importante segmento para a sociedade desde o período da Revolução Industrial, sendo o primeiro setor a utilizar a máquina a vapor, o que levou ao avanço desse tipo de modelo industrial. Caracteriza-se por uma produção geograficamente dispersa e impulsionada pelas rápidas mudanças exigidas pelo mercado. O curso em si permite o aperfeiçoamento do profissional, educador e pesquisador, apoiado em formações básica e tecnológica e integradoras.

O setor têxtil no Brasil é um dos responsáveis pelo impulsionamento da economia, sendo necessário profissionais qualificados para atuarem no mercado. Porém, é perceptível a carência de cursos de aperfeiçoamento para a Engenharia Têxtil, e que possui crescente demanda no mercado, não só pela indústria têxtil convencional como também em setores automobilísticos, medicinais, construções civis; aos quais necessitam de profissionais especializados para os desenvolvimentos de têxteis avançados (CREA-AL, 2020) Assim, entender o perfil do aluno ingressante e as expectativas deste com o curso, poderá auxiliar nas adaptações necessárias para formar profissionais cada vez mais aptos para compor 0 mercado de trabalho. 
Portanto, esse trabalho tem por objetivo conhecer o perfil dos discentes do curso de mestrado do primeiro Programa de Pós-graduação em Engenharia Têxtil no Brasil, da Universidade Federal do Rio Grande do Norte (UFRN), das turmas 2019, 2020 e 2021.

\section{METODOLOGIA}

\subsection{Definição da população e amostra}

A população compreende discentes ativos no curso de pós-graduação em Engenharia Têxtil da Universidade Federal do Rio Grande do Norte (UFRN) com entrada nos anos de 2019, 2020 e 2021. A entrada possui um quantitativo padrão com 12 vagas disponíveis, sendo 1 delas para servidores da UFRN. Para verificar os alunos ativos, foi verificado através do site do programa e pela coordenação do curso. Assim, cada ano contém 10, 10 e 12 discentes ativos, respectivamente, totalizando 32 alunos ativos.

Para amostra, foi utilizado como técnica estatística o censo. Segundo Ferreira (2012), é o procedimento que busca analisar os dados de variáveis de toda a população do estudo, sendo bastante usado quando tem-se populações pequenas.

\subsection{Instrumento e Coleta de dados}

Para a coleta de dados, o instrumento utilizado foi um questionário elaborado pelos autores deste estudo, através da ferramenta online google forms. Para melhor organização dos dados, o questionário foi dividido em duas seções, sendo elas: dados sociodemográficos e ocupacionais; e escolha e perspectiva do curso. No Quadro 1, podese observar todos os detalhes referentes a cada seção.

Quadro 1 - Estrutura do questionário

\begin{tabular}{|c|c|c|}
\hline Seção & Tipo de informação & Questionamentos \\
\hline 1 & $\begin{array}{l}\text { Dados sociodemográficos e } \\
\text { ocupacionais }\end{array}$ & $\begin{array}{l}\text {-Gênero; } \\
\text {-Idade; } \\
\text {-Cidade e Estado de Origem; } \\
\text {-Curso de Nível superior que já realizou; } \\
\text {-Possui vínculo empregatício?; } \\
\text {-Trabalha ou já trabalhou na Área Têxtil?; }\end{array}$ \\
\hline II & $\begin{array}{l}\text { Escolha e perspectiva do } \\
\text { curso }\end{array}$ & $\begin{array}{l}\text {-Como conheceu o curso?; } \\
\text {-Porque escolheu o curso?; } \\
\text {-Turma de ingresso; } \\
\text {-É bolsista ou pretende ter bolsa?; } \\
\text {-Qual área pretende seguir?; } \\
\text {-Se pudesse escolher, qual seria o melhor horário para cursar as } \\
\text { disciplinas da pós-graduação em Engenharia Têxtil?; } \\
\text {-Em uma escala de } 0 \text { a 10, qual a importância do curso de pós- } \\
\text { graduação para sua carreira?; }\end{array}$ \\
\hline
\end{tabular}

Fonte: Autoria própria (2021).

questionário foi disponibilizado por e-mail e em grupos das turmas nas redes sociais com o objetivo de atingir todos os alunos. Como análise, utilizou-se do método qualitativo, pois foram realizadas análises sobre as respostas dos participantes (PEREIRA et al., 2018). 


\section{$3 \quad$ RESULTADOS E DISCUSSÕES}

Foram obtidas 26 respostas na coleta de dados, correspondendo a taxa de resposta de $81,2 \%$ do total de alunos. Logo, os resultados discutidos serão baseados nessa amostra populacional.

De acordo com a Figura 1, é possível perceber que a maior parte dos integrantes do curso são do gênero feminino, representando $65,4 \%$. Ao compararmos com o estudo do perfil dos ingressantes dos cursos de Engenharia Têxtil nas universidades federais, a busca por esses cursos segue sendo predominantemente pelo público feminino (BISPO; FERREIRA; OLIVEIRA, 2020). Em relação à idade, temos discentes entre 21 a 64 anos, em que a maioria possui menos de 30 anos, apresentando maior frequência na faixa de 26 a 30 anos.

Figura 1 - Identificação por gênero e idade.

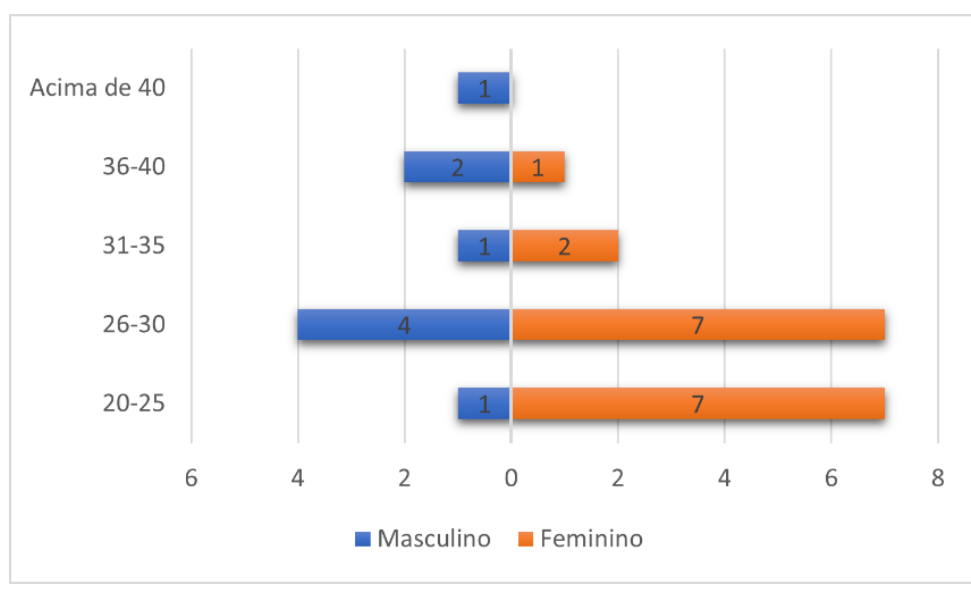

Fonte: Autoria própria (2021).

Quanto à análise da quantidade de alunos por estado (Figura 2a), verifica-se que a maioria dos alunos (61,54\%) são do estado do Rio Grande do Norte, sendo que 42,3\% da cidade sede da instituição, Natal. Nota-se que uma grande parcela dos alunos tem o estado de origem da região nordeste (BA, CE, MA, PB e PI), representando 26,92\%. Enquanto que $11,54 \%$ são de estados da região sudeste do país (SP e RJ). É possível perceber que em 2021 ocorreu o aumento de alunos originários de outros estados, isso pode ter ocorrido, principalmente, pela flexibilidade das aulas que por enquanto estão sendo ministradas de forma remota.

No que diz respeito ao curso superior realizado pelos discentes (Figura 2b), a maioria é proveniente da área de engenharia, correspondendo a 53,84\%. Sendo da Engenharia Têxtil correspondendo a 38,46\%. Em relação a outros cursos da área têxtil, tem-se que $23,08 \%$ de Design de Moda e 3,84\% de Tecnologia Têxtil. Das outras engenharias, 11,54\% são de Produção e 3,84\% de Biomédica. Podemos destacar alunos advindos de cursos como licenciatura em Química, Administração e Gestão Ambiental.

Figura 2- Quantidade de alunos por estado de origem (a) e curso de nível superior que realizou (b). 


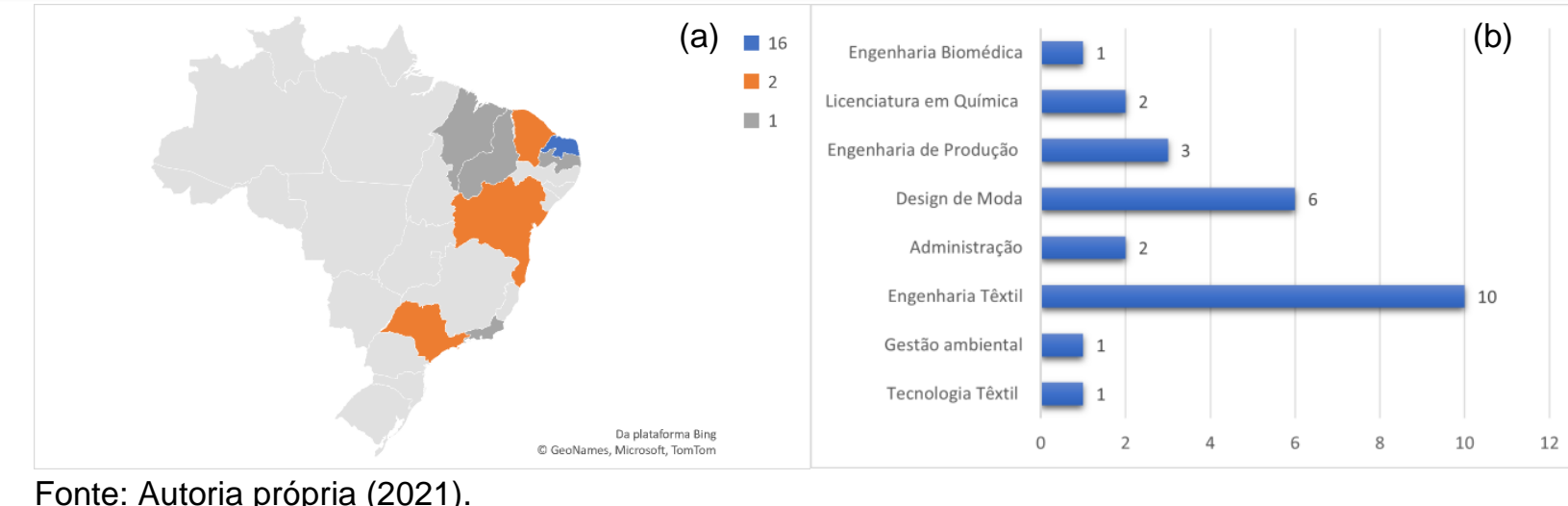

(b)

Fonte: Autoria própria (2021).

Com relação ao vínculo empregatício dos discentes (Figura 3a), mostra que metade (50\%) dos discentes trabalham. De acordo com a Figura 3b, 23,07\% estão trabalhando na área têxtil; $30,77 \%$ já trabalharam na área; enquanto $46,15 \%$ nunca trabalharam na área.

Figura 3- Possui vínculo empregatício (a) e trabalha ou já trabalhou na área (b).

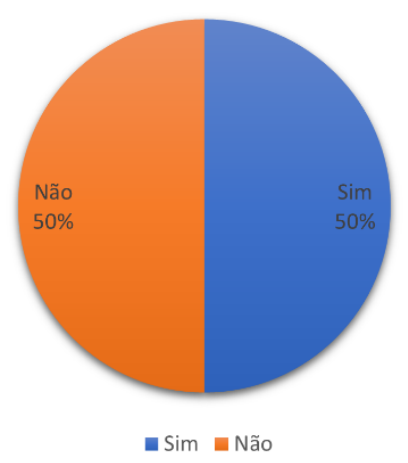

(a)

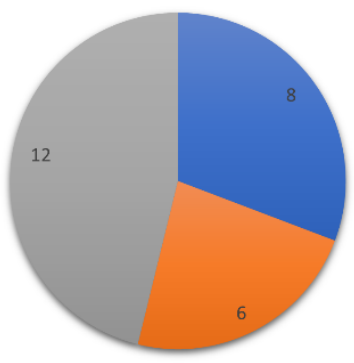

(b)

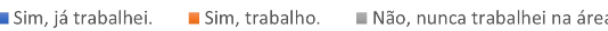

Fonte: Autoria própria (2021).

Em relação a como conheceram o curso (Figura 4a), 46,16\% afirmaram através dos professores do curso de Engenharia Têxtil, 26,92\% pelas mídias eletrônicas e 15,38\% por indicações de amigos e familiares; também conheceram através de eventos $(7,69 \%)$ e tendo sido professora temporária no curso de graduação. Já na Figura $4 \mathrm{~b}$, quando indagados do porquê de escolher o curso, $46,15 \%$ responderam parar melhor qualificação e/ou aprofundar os conhecimentos; $30,77 \%$ tem interesse pela área têxtil; $15,38 \%$ pretende trabalhar na área; e 7,69\% relataram que era a única opção no momento do ingresso. Percebe-se que os que pretendem trabalhar na área são todos ingressantes em 2021, o que pode ser relacionado a novas perspectivas no segmento têxtil que surgiram no mercado devido a pandemia como, por exemplo, a produção de máscaras faciais.

Figura 4- Como conheceram o curso (a) e porque escolheram o curso (b). 


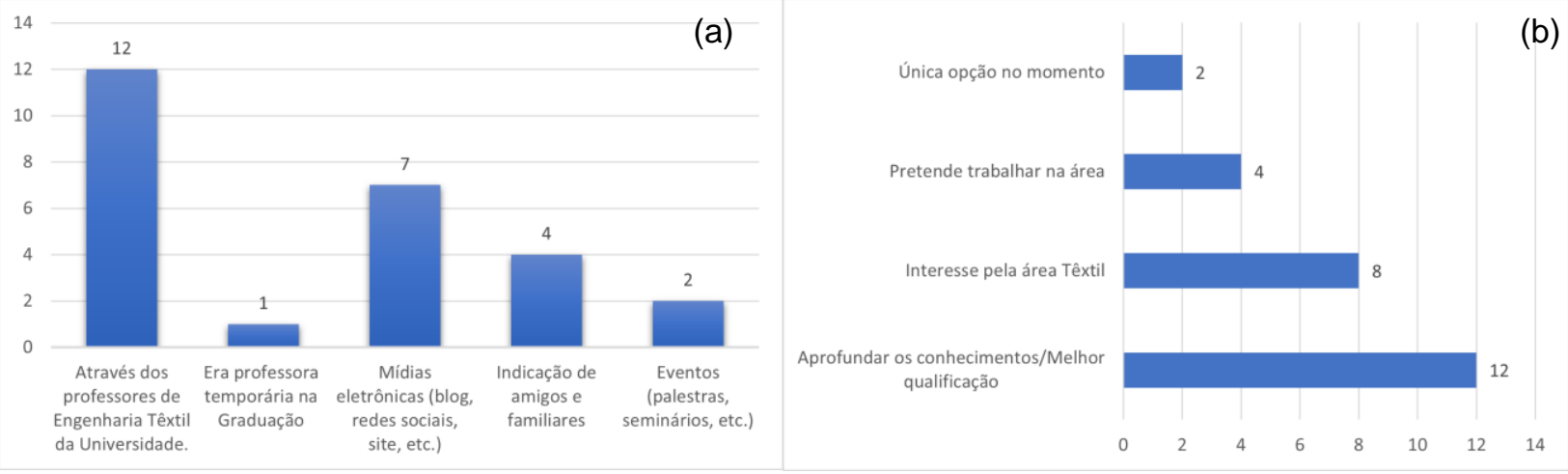

(b)

Fonte: Autoria própria (2021).

De acordo com a Tabela 1, buscou verificar aspectos sobre o curso. A maior parte dos respondentes foram da turma do ano de 2020. Sobre bolsas, a quantidade de bolsistas é de $19,2 \%$, os que pretendem ter bolsa equivalem a $30,8 \%$, enquanto os que não pretendem ter bolsa equivalem a $50 \%$ dos alunos. A demanda de bolsas normalemente equivale a 3 por entrada, aspecto que pode ter sofrido alteração devido a pandemia. $\mathrm{Na}$ preferência do horário das disciplinas, mais da metade $(53,8 \%)$ prefeririam ter aula no período noturno. Porém, o curso funciona nos horários diurnos. Assim, foi possível relacionar que as pessoas que trabalham são as que preferem as aulas no turno da noite. Enquanto das pessoas que não trabalham, uma pequena parcela tem bolsa $(19,2 \%)$ e a outra parcela pretende ser bolsista.

Tabela 1- Turma de ingresso, pretensão de bolsa e preferência de horário.

\begin{tabular}{ccc|ccc|ccc}
\hline \multicolumn{3}{c|}{ Turma de ingresso } & \multicolumn{3}{|c|}{ É bolsista ou pretende ser } & \multicolumn{3}{|c}{ Preferência do horário } \\
& NNo & $\%$ & & No & $\%$ & & No & $\%$ \\
$\mathbf{2 0 1 9 . 1}$ & 7 & 26,9 & Sim, sou & 5 & 19,2 & Matutino & 8 & 30,8 \\
$\mathbf{2 0 2 0 . 1}$ & 11 & 42,3 & Sim, pretendo & 8 & 30,8 & Vespertino & 4 & 15,4 \\
$\mathbf{2 0 2 1 . 1}$ & 8 & 30,8 & Não & 13 & 50 & Noturno & 14 & 53,8 \\
\hline
\end{tabular}

Dentre as áreas que pretendem seguir (Figura 5a), 57,69\% pretende seguir como profissão a área acadêmica, ao passo que $42,31 \%$ pretendem seguir na área profissional. A maior parte dos discentes acreditam que o curso de pós-graduação em Engenharia Têxtil é de suma importância para a carreira tanto no âmbito profissional como no acadêmico, podendo ser observado na Figura $5 \mathrm{~b}$. Esses aspectos demonstram que o objetivo da criação do curso está atrelado as intenções dos discentes do mestrado.

Figura 5- Qual área pretende seguir (a) e escala da importância do curso para a carreira (b). 
(a)

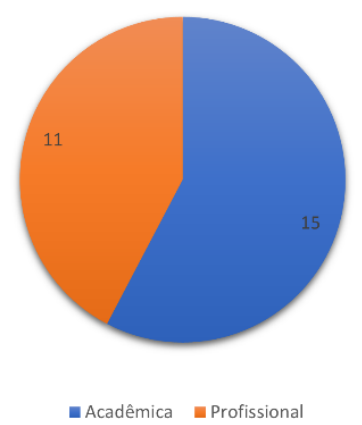

(b)

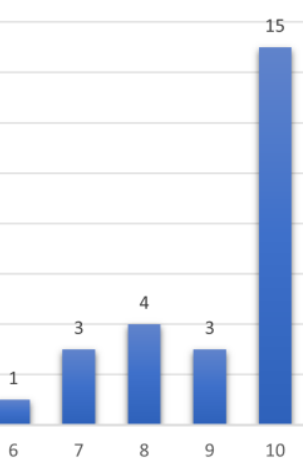

Fonte: Autoria própria (2021).

\section{CONSIDERAÇÕES FINAIS}

Este trabalho buscou analisar o perfil dos discentes do curso de mestrado do Programa de Pós-graduação em Engenharia Têxtil da Universidade Federal do Rio Grande do Norte (UFRN). Os alunos que foram submetidos para essa pesquisa, são alunos das turmas dos seguintes semestres: 2019.1, 2020.1 e 2021.1. Desta forma, foram verificadas características tanto pessoais quanto acadêmicas/profissionais dos futuros mestres.

Através das respostas obtidas, foi possível concluir que o curso superior de graduação que os alunos realizaram abrange diversas áreas, não somente a Engenharia Têxtil. Isso mostra que o interesse pela escolha do mestrado nesta área é multidisciplinar, tendo profissionais diversificados. A pesquisa apresentou perfis também diversificados quanto à idade, ocupação e motivações para a escolha do curso. Identificou-se que a maior parte dos discentes consideram o curso de suma importância para seu aperfeiçoamento acadêmico e profissional, visto o interesse em seguir na área acadêmica e mercado de trabalho.

Conclui-se, então, que a área de Engenharia Têxtil é tão importante na sociedade quanto os demais cursos, e que vai além dos têxteis convencionais como tecidos para roupas, cama, mesa e banho, mas aos têxteis avançados (área de concentração do mestrado), em que as propriedades dos materiais são mais importantes, e assim desenvolvem-se materiais a base de fibras que podem ser aplicados em diversas áreas como: medicina, esporte, arquitetura, engenharia civil, entre outras. Novas tecnologias podem ser utilizadas aliadas aos têxteis como a nanotecnologia. A utilização de novos acabamentos têxteis para obtenção de tecidos com propriedades antivirais, anti odorizantes, inseticidas, antimicrobianos, dentre diversos outros. Além disso, podem ser desenvolvidos materiais com fibras de alto desempenho visando aplicações técnicas como colete a prova de balas, roupas anti chamas, proteção ultravioleta entre outros. Essas possibilidades enfatizam o potencial do curso de mestrado em Engenharia Têxtil em novos desenvolvimentos e inovações.

Mediante a análise dos perfis dos estudantes, e tendo em vista que há apenas dois cursos de mestrado em Engenharia Têxtil no Brasil, os dados obtidos são relevantes para compreender a percepção dos mestrandos em relação ao curso. Através dos resultados, é possível auxiliar a coordenação a entender o perfil desses alunos, traçando métodos significativos para contribuir no processo de ensino e aprendizagem desses discentes, para implementação de novas metodologias de ensino e pesquisa. Assim, formando profissionais de excelência, capacitados para desenvolver seu papel na sociedade de maneira eficiente, desempenhando atividades relacionadas à ciência e tecnologia têxtil no mercado e na academia. 


\section{Agradecimentos}

Agradecemos aos discentes e coordenador do curso de Pós-graduação em Engenharia Têxtil da Universidade Federal do Rio Grande do Norte (UFRN), pela disponibilidade em contribuir nesta pesquisa, respondendo o questionário enviado.

\section{REFERÊNCIAS}

BISPO, Lucas G. M.; FERREIRA, leda; OLIVEIRA, Fernando R. Perfil Dos Ingressantes Dos Cursos De Engenharia Têxtil De Universidades Federais. In: XLVIII Congresso Brasileiro de Educação em Engenharia, 2020. Anais. Disponível em:

http://www.abenge.org.br/sis artigo doi.php?e=COBENGE\&a=20\&c=3139. Acesso em 30 de abr de 2021.

BRASIL. Lei de Diretrizes e Bases da Educação Nacional, LDB.

9394/1996. Disponível em: http://www.planalto.gov.br/ccivil 03/Leis/L9394.htm.

CREA-AL. Engenharia Têxtil: poucos cursos, grande demanda. Disponível em: <https://www.crea-al.org.br/2020/01/engenharia-textil-poucos-cursos-grande-demanda/>. Acesso em 09 mai 2021

FERREIRA, C. S. Elementos de Estatística. Universidade Federal de Juiz de Fora, Departamento de Estatística. Disponível em:

<http://www.ufjf.br/clecio_ferreira/files/2012/04/Cap1-Amostragem1.pdf> Acesso em 09 mai 2021

PEREIRA, A. S.; SHITSUKA, D. M.; PARREIRA, F. J.; SHITSUKA, R. Metodologia da pesquisa científica. 1. ed. - Santa Maria, RS: UAB/UFSM/NTE, 2018. Disponível em: <https://repositorio.ufsm.br/bitstream/handle/1/15824/Lic_Computacao_MetodologiaPesqu isa-Cientifica.pdf?sequence $=1 \&$ isAllowed $=y .>$

UFRN. Apresentação do programa de Pós-graduação em Engenharia Têxtil. Disponível em: < https://sigaa.ufrn.br/sigaa/public/programa/apresentacao.jsf?lc=pt_BR\&id=10480> Acesso em: 07 mai 2021.

UFSC. Projeto Político Pedagógico do Curso de Engenharia Têxtil da Universidade Federal de Santa Catarina, Blumenau - SCC, 2013. Disponível em: $<$ https://textil.blumenau.ufsc.br/files/2014/05/XXPPC-2017-Engenharia-Textilvers\%C3\%A3o-PROGRAD-correcao.pdf> Acesso em: 08 mai 2021

UFSC. Linhas de pesquisa. Disponível em: < https://pgetex.blumenau.ufsc.br/linhas-depesquisa/>. Acesso em 08 mai 2021 


\title{
PROFILE OF STUDENTS IN THE TEXTILE ENGINEERING GRADUATE PROGRAM OF
} UFRN

\begin{abstract}
This work aimed to evaluate the profile of the students of the postgraduate program in Textile Engineering at the Federal University of Rio Grande do Norte (UFRN). With that purpose, data were collected by means of a questionnaire made available to students in classes 2019.1, 2020.1 and 2021.1. The method for interpreting the data was qualitative based on the population sample. As a result, it was possible to observe that most of the students are female, with a predominance below 30 years old, mainly from Rio Grande do Norte. On higher education in general are engineers, mainly textiles, followed by professions related to the area. Many have never worked in the area, as far as employment is concerned, half are working while taking the course and a small portion are scholarship holders. Regarding the course, many knew it through professors of the undergraduate course or through electronic media. The choice is mainly related to the deepening of knowledge, having a better qualification and interest in the area. Most of them intend to pursue an academic career and believe that the course is fundamental to their profession. The data obtained are of great importance to evaluate the profile of the students, the relevance of the course for the textile area, as well as a study so that the university can understand the expectations of the students and take actions to meet them, and thus supply the market with professionals specialized in the textile area.
\end{abstract}

Keywords: Student profile, Post-graduation, Textile Engineering, Choice of course, Motivation. 